\title{
Investigation of the Possibility to Use Ge p-i-n Photodiodes in Infrared SPR Sensors
}

\author{
Artem Fedorenko, Glib Dorozinsky, Hanna Dorozinska, Natalia Kachur, and Volodymyr Maslov
}

\section{ABSTRACT}

Considered in this work are the possibility and advantages of applying a Ge photodiode to measure the surface plasmon resonance (SPR) in the near infrared range (IR). The investigations were performed using the prototype of IR SPR refractometer that operates with two fixed wavelengths (1310 and $1552 \mathrm{~nm}$ ) for excitation of surface plasmons in a thin gold film in the Kretschmann optical scheme. The obtained results of experiments enabled us to draw the conclusion that application of the Ge photodiode in the SPR sensor at the wavelength $1.5 \mu \mathrm{m}$ allows increasing the sensitivity and response magnitude as well as widening the dynamic range of this sensor device.

Keywords: Ge photodiode, near infrared range, surface plasmon resonance.
Published Online: August 03, 2021

ISSN: $2684-4451$

DOI : 10.24018/ejphysics.2021.3.4.95

\section{A. Fedorenko}

V. Lashkaroyv Institute of Semiconductor Physics NAS of Ukraine, Kyiv, Ukraine.

(e-mail: aaartemaa@gmail.com)

G. Dorozinsky

V. Lashkaroyv Institute of Semiconductor Physics NAS of Ukraine, Kyiv, Ukraine.

(e-mail: gvdorozinsky@ukr.net)

H. Dorozinska

National Technical University of Ukraine "Igor Sikorsky Kyiv Polytechnic Institute", Kyiv, Ukraine.

(e-mail: annakushnir30@ukr.net)

N. Kachur

V. Lashkaroyv Institute of Semiconductor Physics NAS of Ukraine, Kyiv, Ukraine.

(e-mail: natalykachur@gmail.com)

V. Maslov*

V. Lashkaroyv Institute of Semiconductor Physics NAS of Ukraine, Kyiv, Ukraine.

(e-mail: vpmaslov@ukr.net)

*Corresponding Author

\section{INTRODUCTION}

It is known that plasmonics is now the field of extraordinary active investigations [1]. Majority of the available SPR devices is designed using the Kretschmann optical scheme with the fixed wavelength of p-polarized light in the configuration for scanning the angle, which is necessary to visualize the phenomenon of total internal reflection at the boundary "dielectric-studied medium". In this case, SPR devices can operate with various wavelengths taken, for example, from the very promising IR range [2]. The obvious advantage of SPR-sensors operating in this range is the possibility to study biological objects [3]. Besides, in particular cases, it can be expected increasing the sensitivity of bio-detectors based on the SPR phenomenon when transferring from resonances observed in the visible range to those in the IR range $[4,5]$. It is possible owing to the following factors:

1. Majority of bio-molecules possesses specific peaks of absorption in the IR range. Therefore, when carrying out investigations for various wavelengths in this range and juxtaposing the results with the known absorption spectra of bio-molecules, it becomes possible to make selective research of molecules in the studied substances.

2. In the first approximation, the plasmon path length is proportional to the wavelength of light incident onto the prism. According to it, the path length for plasmons excited with the IR light becomes longer, which can provide an additional positive effect on the sensitivity of bio-detectors.

3. To provide a high sorption capability, the gold coatings are prepared to be relatively "thick" (their thickness often exceeds $50 \mathrm{~nm}$ ) as compared with the effective depth of surface plasmon penetration into the studied substance [6]. It results not only in decreasing the electric field at the surface of this coating but in widening the resonance characteristics of reflection as well as enhancing the intensity of reflected light near the resonance angle, which influences on the SPRsensor response amplitude and increases the error in determining the position of resonance angle. When using the IR range, the optimum thickness of the gold film can be decreased approximately to $30 \mathrm{~nm}$ [7].

The above advantages need to be experimentally checked accordingly to the specific wavelength and chosen photodetector.

It is known that the wavelength $1.5 \mu \mathrm{m}$ is promising for application in SPR sensors [8], [9]. Operation of the device 
at this wavelength provides additional constructive possibilities, for instance, using the optical fibers [10], [11].

To perform studying the SPR features at the wavelength $1.5 \mu \mathrm{m}$, we used a Ge fast-response $\mathrm{p}-\mathrm{i}-\mathrm{n}$ photodiode designed at the V. Lashkaryov Institute of Semiconductor Physics, NAS of Ukraine [12], also we compared it with the serial Ge photodiode, and both were tested for operation at the wavelengths 1310 and $1552 \mathrm{~nm}$.

The aim of this work was to study the possibility to apply the developed photodiode for SPR investigations within the near infrared range as well as advantages of the SPR sensor based on it in comparison with sensors operating in the visible range.

\section{MATERIALS AND METHODS}

The measurements were performed using the prototype of IR SPR refractometer operating at the fixed wavelength for excitation of surface plasmons in a thin gold film used in the Kretschmann optical scheme (Fig. 1) with angle modulation.

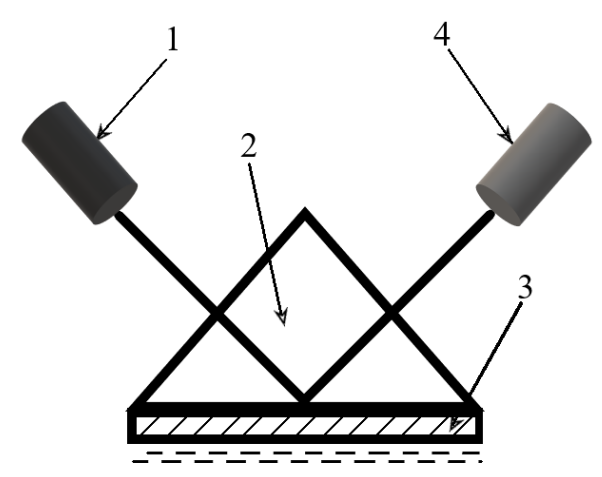

Fig. 1. Scheme of measurement.

The main constructive optical elements of this scheme were as follows: the source of monochromatic p-polarized light - semiconductor laser 1, connective prism 2 from glass $\Phi 1$, which provides total internal reflection, thin gold film 3 of the optimal thickness $(37 \mathrm{~nm})$ that was deposited using thermal evaporation in vacuum onto the operation face of connective prism and was carrying the surface plasmons excited by laser radiation. The photodiode 4 was used for measuring the intensity of light reflected from the gold film. That enabled to plot the photometric characteristics (reflection curves). Changing the angle of laser beam incidence onto the gold film from the side of connective prism was provided by simultaneous rotation of the laser source and photodetector. Applied in these measurements were two lasers with different wavelengths 1310 and 1552 $\mathrm{nm}$. The rated optical power of these lasers was the same $10 \mathrm{~mW}$. The measurements were performed with two diodes, namely: serial Ge p-n diode FD 6G as well as the developed Ge p-i-n diode FDG-2 with an additional silicon filter (Table I).

The photodetectors chosen for researches were used in the photodiode regime with the constant backward bias equal to $0.13 \cdot \mathrm{U}_{\text {rmax }}$. For the photodiode FDG-2, this value was equal to $2.6 \mathrm{~V}$, while for FD-6G $-1.3 \mathrm{~V}$. The voltage drop on the measuring resistor connected in series with the photodiode was inputted to ADC module Arduino NANO and then to the computer via the USB port.

\begin{tabular}{ccccccc}
\multicolumn{8}{c}{ TABLE I: THE ARRANGEMENT OF CHANNELS } \\
\hline $\begin{array}{c}\text { Photo- } \\
\text { diode }\end{array}$ & $\begin{array}{c}\text { Central } \\
\text { wave- } \\
\text { length, } \\
\mu \mathrm{m}\end{array}$ & $\begin{array}{c}\text { Operation } \\
\text { range, } \\
\mu \mathrm{m}\end{array}$ & $\begin{array}{c}\text { Reverse } \\
\text { voltage, } \\
\mathrm{V}\end{array}$ & $\begin{array}{c}\text { Dark } \\
\text { current, } \\
\mu \mathrm{A}\end{array}$ & $\begin{array}{c}\text { Time } \\
\text { cons- } \\
\text { tant, } \\
\mu \mathrm{s}\end{array}$ & $\begin{array}{c}\text { Sensi- } \\
\text { tivity, } \\
\mu \mathrm{A}\end{array}$ \\
\hline $\begin{array}{c}\text { FDG- } \\
2\end{array}$ & 1.54 & $1.15 \ldots 1.7$ & 20 & 1 & 0.004 & 40 \\
$\begin{array}{c}\text { FD- } \\
6 \mathrm{G}\end{array}$ & 1.5 & $0.4 \ldots 1.8$ & 10 & 13 & 5 & 7 \\
\hline
\end{tabular}

\section{RESULTS AND DISCUSSION}

The measured with the prototype of IR SPR refractometer reflection characteristics inherent to distilled water are shown in Fig. 2. These plots show that both studied photodiodes with $\mathrm{p}-\mathrm{n}$ and $\mathrm{p}-\mathrm{i}-\mathrm{n}$ structures provide typical narrowing the reflection curves as well as the shift of their minima to the side of lower angles when increasing the wavelength of radiation exciting surface plasmons.

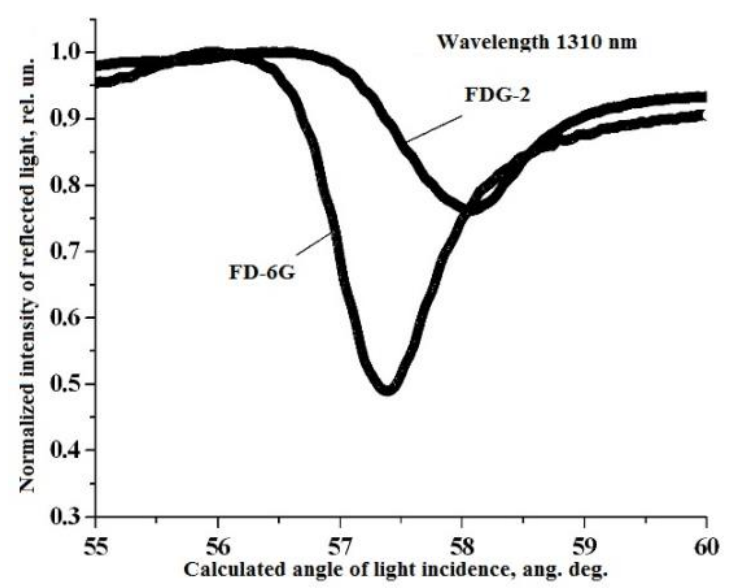

(a)

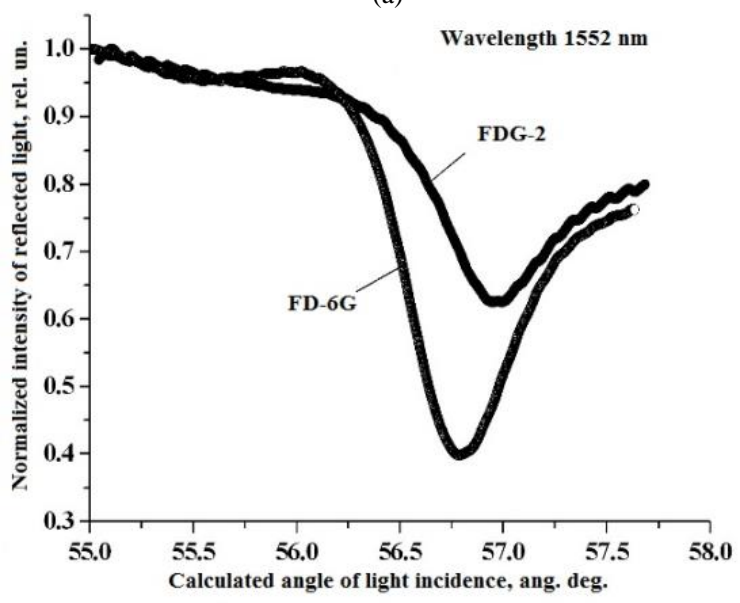

(b)

Fig. 2. Reflection curves measured with the Ge photodetectors FD-6G and FDG-2 for two wavelengths of light exciting surface plasmons: 1310 (a) and $1552 \mathrm{~nm}(\mathrm{~b})$.

The substitution kinetics for changing the distilled water with the water solution of sodium chloride $(9 \mathrm{mg} / \mathrm{mL})$ in the measuring cuvette of refractometer prototype are adduced in Fig. 3 and 4.

When using the longer wavelength $1552 \mathrm{~nm}$, instead of $1310 \mathrm{~nm}$, it was observed not only increasing the sensitivity of sensor but decreasing the temperature drift of base line, too. 


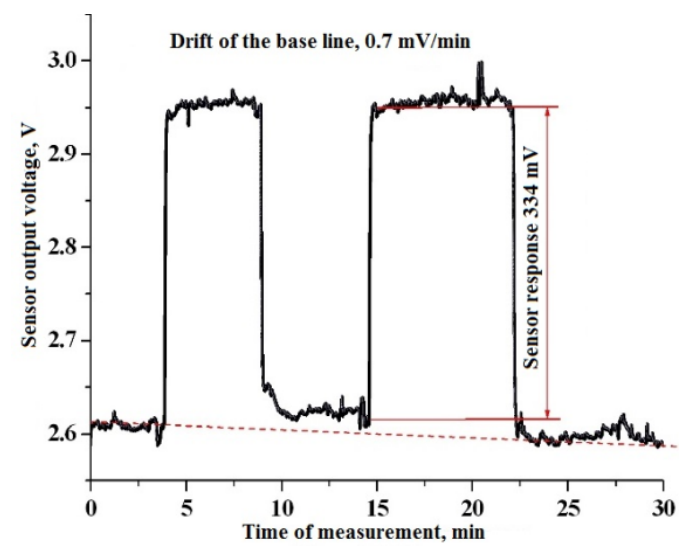

(a)

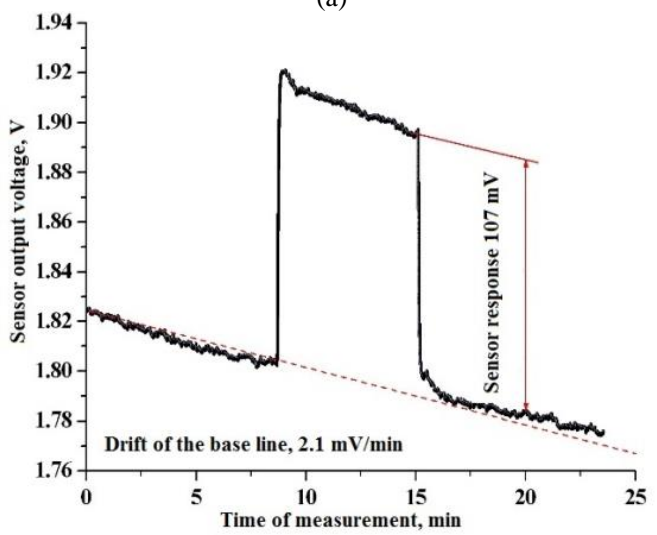

(b)

Fig. 3. Measured with the SPR sensor kinetic curves for the wavelength $1310 \mathrm{~nm}$ exciting surface plasmons when substituting the distilled water with physiological saline $(9 \mathrm{mg} / \mathrm{mL})$ for photodetectors FDG-2 (a) and FD-6G (b).

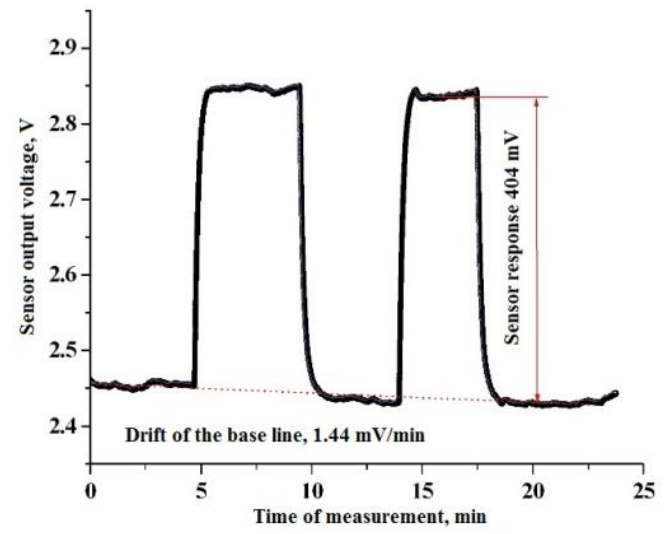

(a)

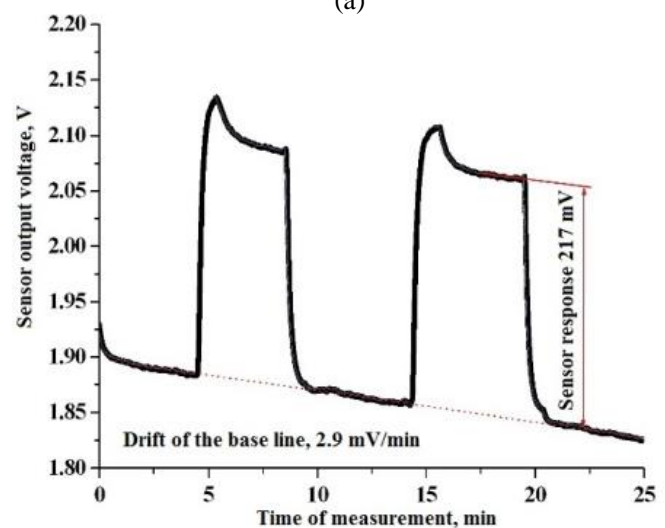

(b)

Fig. 4. Measured with the SPR sensor kinetic curves for the wavelength $1552 \mathrm{~nm}$ exciting surface plasmons when substituting the distilled water with physiological saline $(9 \mathrm{mg} / \mathrm{mL})$ for photodetectors
The summarized data of investigations are adduced in Tables II and III.

TABLE II: MEASURED PARAMETERS OF SPR SENSORS FOR TWO WAVELENGTHS

\begin{tabular}{ccccccc}
\multicolumn{7}{c}{ WAVELENGTHS } \\
\hline $\begin{array}{c}\text { Wave- } \\
\text { length, } \\
\text { nm }\end{array}$ & $\begin{array}{c}\text { Photo- } \\
\text { diode }\end{array}$ & $\begin{array}{c}\text { Angle of the } \\
\text { SPR curve } \\
\text { minimum, } \\
\text { ang. deg. }\end{array}$ & $\begin{array}{c}\text { Sensor } \\
\text { response, } \\
\mathrm{mV}\end{array}$ & $\begin{array}{c}\text { Dynamic } \\
\text { range, } \\
\mathrm{mV}\end{array}$ & $\begin{array}{c}\text { Operation } \\
\text { range, } \\
\text { ang. deg. }\end{array}$ & $\begin{array}{c}\text { Drift } \\
\text { velocity, } \\
\mathrm{mV} / \mathrm{min}\end{array}$ \\
\hline \multirow{2}{*}{1310} & FDG-2 & 58.062 & 107 & 626 & 3.938 & -2.1 \\
& FD-6G & 57.394 & 334 & 1326 & 4.606 & -0.7 \\
1552 & FDG-2 & 56.962 & 217 & 1220 & 5.038 & -2.9 \\
& FD-6D & 56.789 & 404 & 2241 & 5.211 & -1.44 \\
\hline
\end{tabular}

TABLE III: CHANGE IN THE SPR SENSOR PARAMETERS WHEN TRANSFERRING FROM THE WAVELENGTH 1310 UP TO 1552 NM

\begin{tabular}{ccccc}
\hline Photodiode & $\begin{array}{c}\text { Sensor } \\
\text { response, } \\
\text { times }\end{array}$ & $\begin{array}{c}\text { Operation } \\
\text { range, } \%\end{array}$ & $\begin{array}{c}\text { Drift velocity, } \\
\text { times }\end{array}$ & $\begin{array}{c}\text { Dynamic } \\
\text { range, times }\end{array}$ \\
\hline FDG-2 & 2 & 28 & 1.4 & 1.95 \\
FD-6G & 1.2 & 13 & 2.1 & 1.69 \\
\hline
\end{tabular}

In addition, we performed determination of the sensitivity inherent to the SPR sensor equipped with the photodetector FDG-2 to glucose at the wavelength $1310 \mathrm{~nm}$. As objects of investigations, we chose water solutions of glucose with the concentrations within the range $0.1 \ldots 0.5 \mathrm{mg} / \mathrm{mL}$. The measured reflection curves for various operation regimes of laser and the concentration dependence of the SPR sensor response are shown in Figure 5 as well as parameters of laser operation regimes and the values of SPR resonance angles in Table IV.

TABLE IV: PARAMETERS OF LASER AND PHOTODIODE OPERATION

REGIMES AS WELL AS THE VALUES OF SPR RESONANCE ANGLES

\begin{tabular}{|c|c|c|c|c|c|c|c|c|c|}
\hline \multirow[t]{2}{*}{ No } & \multicolumn{4}{|c|}{ Laser regime } & \multicolumn{3}{|c|}{ Photodiode regime } & \multicolumn{2}{|c|}{$\begin{array}{c}\text { Resonance } \\
\text { angles, } \\
\text { ang. deg. }\end{array}$} \\
\hline & $U_{\mathrm{L}}, \mathrm{V}$ & $\begin{array}{c}I_{\mathrm{L}}, \\
\mathrm{mA}\end{array}$ & $\begin{array}{l}P_{\mathrm{L}}, \\
\mathrm{mW}\end{array}$ & $\begin{array}{r}I_{\mathrm{PDL}} \\
\mathrm{mA}\end{array}$ & $\begin{array}{l}I_{\mathrm{R}} \\
\mu \mathrm{A}\end{array}$ & $\begin{array}{c}U_{\mathrm{R}}, \\
\mathrm{V}\end{array}$ & $\begin{array}{l}P_{\mathrm{PD}}, \\
\mu \mathrm{W}\end{array}$ & $\theta_{\mathrm{SP}}$ & $\Delta \theta$ \\
\hline 1 & 1.015 & 12.338 & 2.4676 & 0.2239 & 56 & 0.723 & 40.488 & 57.423 & 0.56 \\
\hline 2 & 1.060 & 24.037 & 4.8074 & 0.5072 & 184 & 0.727 & 133.768 & 57.433 & 0.69 \\
\hline 3 & 1.127 & 41.454 & 8.2908 & 0.9016 & 368 & 0.674 & 248.032 & 57.45 & 0.81 \\
\hline & 1.160 & 50.000 & 10.0000 & 1.1420 & & & 500 & & \\
\hline
\end{tabular}

The chosen regimes of laser operation were provided by changing the applied voltage $\mathrm{U}_{\mathrm{L}}$ not exceeding the maximum allowed values (see the fourth line in Table IV). Also adduced in this Table are the operation parameters of photodetector FDG-2: reverse current and voltage, as well as the scattered power that was two-fold lower than the maximum allowed one $(500 \mu \mathrm{W})$. Changing the power had no essential effect on the value of resonance angle $\theta_{\mathrm{SP}}$ but changed the dynamic range of measuring $\Delta \theta$ practically twofold. When using the power $8.3 \mathrm{~mW}$, the sensitivity was 1.7 times higher than that for the power $2.5 \mathrm{~mW}$ due to the steeper left slope of the resonance curve. Therefore, measurements were performed just in this regime. The calculated sensitivity for the chosen regime of measurements was $72 \mathrm{mV} \cdot \mathrm{mg}^{-1} \cdot \mathrm{mL}$, while for the minimum power of laser radiation it was $41 \mathrm{mV} \cdot \mathrm{mg}^{-1} \cdot \mathrm{mL}$. But the deficiency of operation under this relatively high power was a temperature effect on the analyte, which caused some drift of the base line. 


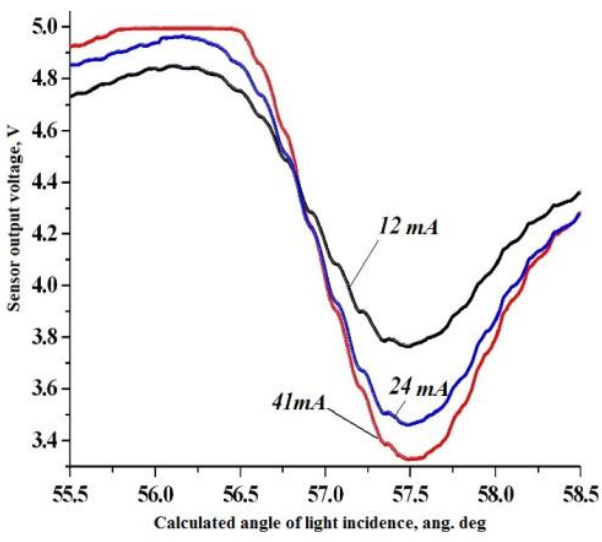

(a)

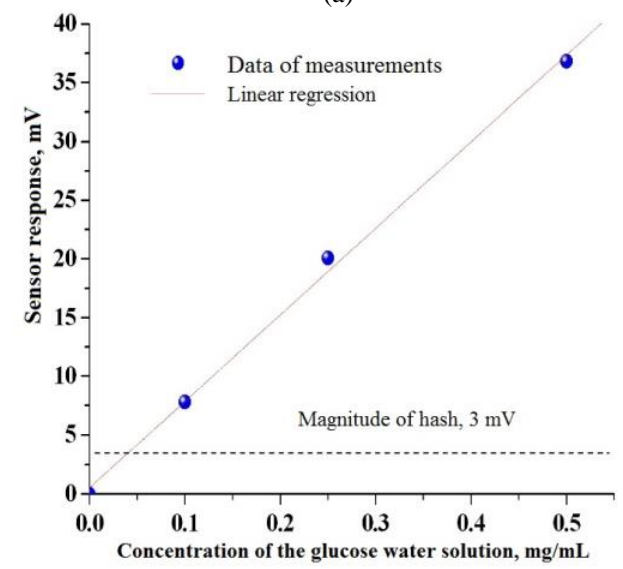

(b)

Fig. 5. Measured reflection curves for various operation regimes of laser (a) and the dependence of the SPR sensor response (b) for the concentration of glucose solutions $0.1,0.25$ and $0.5 \mathrm{mg} / \mathrm{mL}$

Shown in Fig. 6 is the kinetic curve of SPR sensor response corresponding to substitution of distilled water with the glucose solution $(0.1 \mathrm{mg} / \mathrm{mL})$, where the temperature drift of the base line is clearly pronounced $(1.8 \mathrm{mV} / \mathrm{min})$.

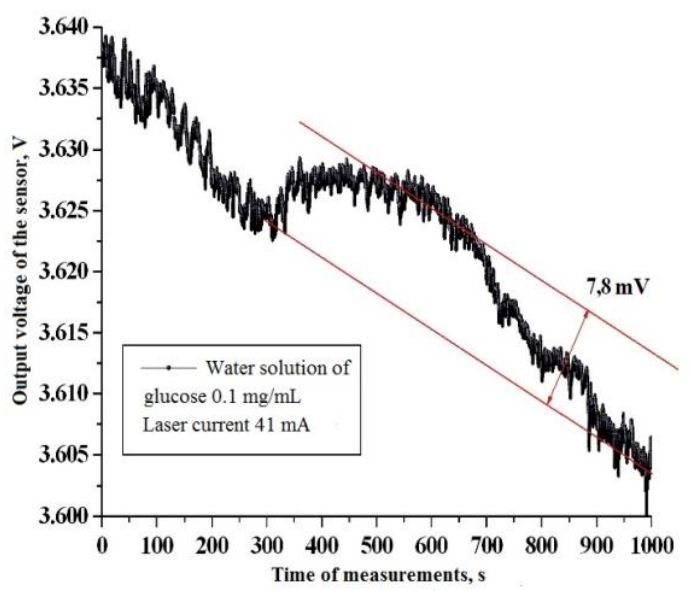

Fig. 6. Drift of the base line typical for the measured SPR characteristics.

Thus, to minimize the temperature effect of laser radiation on analyte and provide the maximum sensitivity as well as dynamic range of measurements for this sensor, it is necessary to optimize the measurement regimes, in particular, the voltage applied to the laser, the bias voltage on the photodiode and resistance of the measuring resistor. Besides, it is important to minimize the effect of ADC module Arduino NANO.
The measured kinetic made it possible to determine the magnitude of hash $(3 \mathrm{mV})$ as well as the lower limit of detecting the concentration of glucose in water (0.05 mg/mL).

It was experimentally ascertained that the increase in laser radiation power from 2.5 up to $8.3 \mathrm{~mW}$ enhances both the sensitivity to glucose by 1.7 times (from $41 \mathrm{mV} \cdot \mathrm{mg}^{-1} \cdot \mathrm{mL}$ to $72 \mathrm{mV} \cdot \mathrm{mg}^{-1} \cdot \mathrm{mL}$ ) and dynamic range of measurements at the left slope of resonance curve by 1.45 times (from 0.56 up to 0.81 ang. deg.). The lower limit of detecting the concentration of glucose in water is $0.05 \mathrm{mg} / \mathrm{mL}$ for the power of laser radiation $8.3 \mathrm{~mW}$, and the magnitude of hash (in kinetic curve) is only $3 \mathrm{mV}$. At high laser radiation powers, there observed was an essential temperature effect on the analyte, which caused the temperature drift of the base line $(1.8 \mathrm{mV} / \mathrm{min})$. Therefore, when performing specific investigations, it is always necessary to optimize the regimes of investigations, in particular, the voltage applied to the laser, the bias voltage on photodiode and resistance of the measuring resistor to minimize the temperature effect and provide the maximum sensitivity and sufficient dynamic range for measurements with this SPR sensor.

\section{CONCLUSION}

Thus, the obtained results enable to draw the following conclusions about advantages of using the wavelength from the infrared range and application of the designed photodetector FDG-2:

1. Diminishing expenses on gold - for the wavelengths of the visible spectral range (e.g., $650 \mathrm{~nm}$ ) the optimum thickness of the gold film is $49 \mathrm{~nm}$, while for the wavelength $1310 \mathrm{~nm}$ it is $37 \mathrm{~nm}$, and for $1552 \mathrm{~nm}$ - only $34 \mathrm{~nm}$.

2. The higher sensitivity, owing to a higher steepness of the SPR reflection curve slope than that for the wavelengths from the visible range.

3. The wider dynamic range, due to a new developed photodetector FDG-2. For instance, when transferring from the wavelength 1310 to $1552 \mathrm{~nm}$ the dynamic range increases by $15 \%$ larger than for the serial photodetector FD-6G.

4. The higher sensor response, which is provided by using the photodetector FDG-2. E.g., when transferring from the wavelength 1310 to $1552 \mathrm{~nm}$, the SPR sensor response increases by $80 \%$ higher than in the case of commercial photodetector FD-6G. Besides, using the photodetector FDG-2 provides a higher noise immunity.

\section{REFERENCES}

[1] M.L. Dmitruk, S.Z. Malinich, "Surface plasmon resonances and their manifestation in optical properties of noble metal nanostructures," Ukrainskyi fizychnyi zhurnal, vol. 9(1), pp. 3-37, 2014 (in Ukrainian).

[2] S. Franzen, M. Losego, M. Kang, E. Sachet, \&J.-P. Maria, "Infrared Surface Plasmon Resonance," Introduction to Plasmonics, pp. 143167, 2015, doi:10.1201/b18229-7.

[3] R. Ziblat, V. Lirtsman, D. Davidov, B. Aroeti, "Infrared Surface Plasmon Resonance: A Novel Tool for Real Time Sensing of Variations in Living Cells," Biophysical Journal, vol. 90, pp. 25922599, April 2006.

[4] M. Golosovsky, V. Lirtsman, V. Yashunsky, D. Davidov, B. Aroeti, "Midinfrared surface-plasmon resonance-A novel biophysical tool for studying living cell," Journal of Applied Physics, vol. 105, pp. 102036, 2009. 
[5] V. Lirtsman, M. Golosovsky, and D. Davidov, "Infrared surface plasmon resonance technique for biological studies," Journal of Applied Physics, vol. 103, pp. 014702, 2008.

[6] Zh. Zhe, L. Qian, Qi Zhimei "Study of Au-Ag alloy film based surface plasmon resonance sensor with wavelength interrogation in the near infrared region." 2012.

[7] J. Guske, J. Brown, A. Welsh, S. Franzen, "Infrared surface plasmon resonance of AZO-Ag-AZO sandwich thin films," OPTICS EXPRESS, vol. 20(21), pp. 23215-23226, October 2012.

[8] Yi Xu, Lin Wu, Kee Ang Lay, "MoS2-based Highly Sensitive Nearinfrared Surface Plasmon Resonance Refractive Index Sensor," IEEE JOURNAL OF SELECTED TOPICS IN QUANTUM ELECTRONICS, vol. 25(2), pp. 4600307, March/April 2019.

[9] S. Patskovsky, A. Kabashin, M. Meunier, J. Luong, "Near-infrared surface plasmon resonance sensing on a silicon platform," Sensors and Actuators B, vol. 97, pp. 409-414, 2004.

[10] H. Rabiul, A. Sanjida, M. Rahman, "Design of a surface plasmon resonance refractive index sensor with high sensitivity," Optical Engineering, vol. 56(8), pp. 087101, 2017.

[11] Ch. Liu, L. Yang, X. Lu, Q. Liu, F. Wang, J. Lv, T Sun, H Mu, P. Chu "Mid-infrared surface plasmon resonance sensor based on photonic crystal fibers," OPTICS EXPRESS, vol. 25(13), pp. 14227-14237, June, 2017.

[12] V.P. Maslov, A.V. Sukach, V.V. Tetyorkin, et al. "Particularities in manufacturing, electrical and photoelectrical properties of diffusion Ge p-i-n photodiodes," Optoelektronika $i$ poluprovodnikovaya tekhnika, vol. 53, pp. 188 - 198, 2018 (in Ukrainian).

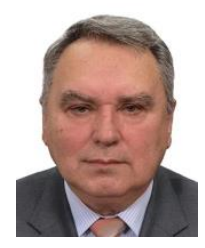

Prof. Volodymyr Maslov, Doctor of Materials Science, Head of the Department of physics and techno-logical basics of sensor materials at the V. Lashkaryov Institute of Semiconductor Physics. Honored inventor of Ukraine. Author of more than 156 publications and more than 400 patents of Ukraine and USSR author's certificates. His research interests include several topics of optical engineering and physical behavior of functional materials as well as phenomena of surface plasmon resonance, with application of it in medicine and ecology.

ORCID: https://orcid.org/0000-0001-7795-6156.

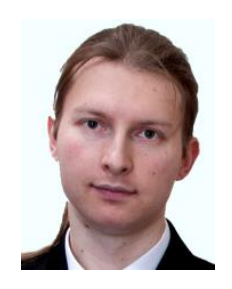

Glib Dorozinsky, PhD, Senior Researcher at the V. Lashkaryov Institute of Semiconductor Physics NAS of Ukraine. Author of more than 68 publications and 28 patents of Ukraine. The area of hisresearch interests in physics of surfaces, development and design of chemical sensors and biosensors. ORCID: https://orcid.org/0000-0002-7881-2493.

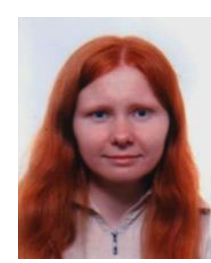

Hanna Dorozinska, PhD. She is an author of 17 publications. Her research interests in optical metrology and development as well as design of chemical sensors and biosensors for application in industry and ecology.

ORCID: https://orcid.org/0000-0002-9352-3761.

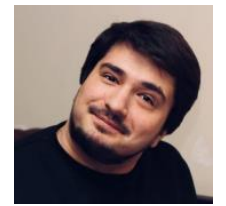

Natalia Kachur got her degree MS in Physics andTechniques at the National Aviation University of Ukraine in 2006. Her research interests includephysics of surfaces, development, and design sensorsfor applying in control of quality of transparent materials.

Artem Fedorenko, received master's degree at theNational Technical University of Ukraine "Igor Sikorsky Kyiv Polytechnic Institute", Ph.D.student at the V. Lashkaryov Institute of Semiconductor Physics, NAS of Ukraine. The area of his scientific interests includes IR photo detectors and laser ranging. 